\section{MyD88/ERK/NFkB pathways and pro-inflammatory cytokines release in periodontal ligament stem cells stimulated by Porphyromonas gingivalis}

Francesca Diomede, ${ }^{1}$ Maria Zingariello, ${ }^{2}$ Marcos F.X.B. Cavalcanti, ${ }^{3}$

Ilaria Merciaro, ${ }^{1}$ Jacopo Pizzicannella, ${ }^{1}$ Natalia de Isla, ${ }^{4}$ Sergio Caputi, ${ }^{1}$ Patrizia Ballerini, ${ }^{5}$ Oriana Trubiani ${ }^{1}$

${ }^{1}$ Department of Medical, Oral and Biotechnological Sciences, University "G. d'Annunzio" Chieti-Pescara, Chieti, Italy ${ }^{2}$ Laboratory of Microscopy and Ultrastructural Analysis, University "Campus Bio-Medico", Rome, Italy ${ }^{3}$ Laboratory of biophotonics applied to health sciences - Nove de Julho University, São Paulo, Brazil ${ }^{4}$ CNRS, UMR 7365 Ingénierie Moléculaire et Physiopathologie Articulaire (IMOPA), Faculté de Médecine, Université de Lorraine, Vandœuvre-lès-Nancy, France 5Department of Psychological, Health and Territorial Sciences, School of Medicine, University "G. d'Annunzio" Chieti-Pescara, Chieti, Italy

\footnotetext{
Abstract

The present study was aimed at investigating whether human Periodontal Ligament Stem Cells (hPDLSCs) were capable of sensing and reacting to lipopolysaccharide from Porphyromonas gingivalis (LPS-G) which is widely recognized as a major pathogen in the development and progression of periodontitis. At this purpose hPDLCs were stimulated with $5 \mu \mathrm{g} / \mathrm{mL}$ LPS-G at various times and the expression of toll-like receptor 4 (TLR4) was evaluated. Toll-like receptors (TLRs) play an essential role in innate immune signaling in response to microbial infections, and in particular TLR4, type-I transmembrane proteins, has been shown recognizing LPS-G. Our results put in evidence, in treated samples, an overexpression of TLR4 indicating that, hPDLSCs express a functional TLR4 receptor. In addition, LPS-G challenge induces a significant cell growth decrease starting from $24 \mathrm{~h}$ until $72 \mathrm{~h}$ of treatment. LPS-G leads the activation of the TLR4/MyD88 complex, triggering the
}

secretion of proinflammatory cytokines cascade as: IL- $1 \alpha$, IL- 8 , TNF- $\alpha$ and $\beta$ and EOTAXIN. Moreover, the upregulation of pERK/ERK signaling pathways and NFkB nuclear translocation was evident. On the basis of these observations, we conclude that hPDLSCs could represent an appropriate stem cells niche modeling leading to understand and evaluate the biological mechanisms of periodontal stem cells in response to LPS-G, mimicking in vitro an inflammatory process occurring in vivo in periodontal disease.

\section{Introduction}

Periodontal ligament, a soft connective tissue located between the tooth root and the alveolar socket, plays a key role in the regenerative processes of cementum and bone. ${ }^{1,2}$

Periodontitis is an inflammatory pathological condition giving rise to gingival inflammation, bleeding, extracellular matrix degradation, bone resorption and tooth loss. ${ }^{3}$ The periodontal pocket is predisposed to the aggressive activities of putative pathogens. This anaerobic gram-negative bacterium, Porphyromonas gingivalis, seems to be involved in periodontitis. Its pathogenicity linked to a wide variety of factors, including lipopolysaccharides (LPS-G), is considered the major player in mediating the pathological events. ${ }^{4,5}$ and has been reported to upregulate proinflammatory cytokines via a toll-like receptor 4 (TLR4)-mediated mechanism. ${ }^{6}$

Within the periodontal tissues there exists a population of human periodontal ligament stem cells (hPDLSCs); we reported that, similarly to other mesenchymal stem cells, hPDLSCs show high self-renewal capability, and have the potential to differentiate into mesengenic lineages. ${ }^{7}$ Moreover, data are being collected on their capability of taking part to tissue regeneration when used with appropriate biomaterials. ${ }^{8,9}$ Few studies have reported the effects of LPS on hPDLSCs, the aim of the present work was to characterize the molecular pathway triggered by LPS-G in hPDLSCs and to evaluate, in the same cells, the production of a wide array of both inflammatory and antiinflammatory molecules induced by LPS-G.

\section{Materials and Methods}

\section{Cell culture}

The study protocol was approved by the Ethics Committee of the University of
Correspondence: Oriana Trubiani, Department of Medical, Oral and Biotechnological Sciences, University, "G. d'Annunzio" ChietiPescara, Via dei Vestini 31, 66100 Chieti, Italy. Fax: +39.0871 .3554033 .

E-mail: trubiani@unich.it

Key words: MyD88; ERK; NFkB; cytokines; LPS-G; hPDLSCs.

Contributions: FD, sample collection; FD, $\mathrm{MZ}, \mathrm{IM}$, experiments performing; FD, MZ, MFXBC, NdI, data analysis, revised manuscript; PB, OT, manuscript writing; SC, OT, study design. All authors have edited, read and approved the final manuscript.

Conflict of interest: the authors declare no conflict of interest.

Acknowledgments: this work has been supported with OT ex $60 \%$ funds, University "G. d'Annunzio". The authors are grateful to Prof. Tania Zulli, University RomaTre for the English revision.

Received for publication: 16 March 2017. Accepted for publication: 18 May 2017

This work is licensed under a Creative Commons Attribution-NonCommercial 4.0 International License (CC BY-NC 4.0).

CCopyright F. Diomede et al., 2017 Licensee PAGEPress, Italy

European Journal of Histochemistry 2017; 61:2791 doi:10.4081/ejh.2017.2791

Chieti (n²66/17.04.14). Periodontal ligament tissue was collected and cultured as previously described by Diomede et al. ${ }^{10}$ to obtain hPDLSCs. Briefly, periodontal ligament tissues were carried out from human premolar teeth in healthy donors. Samples were obtained from horizontal fibers of the periodontal ligament by scraping the teeth roots with a Gracey's curette. Explants were cultured in MSCGM-CD (Lonza, Basel, Switzerland) according to the manufacturer's instructions. ${ }^{11}$ The medium was changed twice a week, and cells spontaneously migrated from explants tissues. Human PDLSCs at $2^{\text {nd }}$ passage were used in all experiments.

\section{LPS challenge}

hPDLSCs were incubated in absence (ctrl) or in presence of $5 \mu \mathrm{g} / \mathrm{mL}$ of LPS-G (InvivoGen, San Diego, CA, USA) for the indicated time periods at $37^{\circ} \mathrm{C}$ in a humidified atmosphere at $5 \% \mathrm{CO}_{2}$. 


\section{MTT assay and Trypan Blue cell viability assay}

Cell viability and proliferation were evaluated as previously described by Trubiani et al. ${ }^{12,13}$ In brief, for MTT assay, $2 \times 10^{3}$ cells/well were seeded into 96-well plates in $200 \mu \mathrm{L}$ medium with LPS-G. At the designated time, 24, 48 and 72h, $20 \mu \mathrm{L}$ MTT (Promega, Milan, Italy) were added to each well and incubated for $4 \mathrm{~h}$. Absorbance at $490 \mathrm{~nm}$ was measured with a reference wavelength of $630 \mathrm{~nm}$. Untreated hPDLSCs were used as control cells.

For trypan blue staining untreated and LPS-G treated hPDLSCs after 24, 48 and 72 $\mathrm{h}$ of culture were incubated with $0.5 \%$ of trypan blue solution for $10 \mathrm{~min}$ at room temperature and subsequently analysed with Burker's chamber.

\section{Immunohistochemistry and Confocal laser scanning microscope (CLSM) analysis}

Cells were processed as previously reported by Trubiani et $a l .{ }^{14}$ in order to be observed at CLSM. Cells grown on glass coverslips were fixed for $10 \mathrm{~min}$ at RT with $4 \%$ paraformaldehyde in $0.1 \mathrm{M}$ sodium phosphate buffer (PBS), pH 7.2. After being washed in PBS, cultures were processed for immunofluorescence labeling. Samples were permeabilized with $0.5 \%$ Triton X-100 in PBS for $10 \mathrm{~min}$, followed by blocking with 5\% skimmed milk in PBS for $30 \mathrm{~min}$. Primary monoclonal antibodies anti-human NFkB (1:200, rabbit), ERK 1/2 (1:100, rabbit), p-ERK $1 / 2$ (1:1000, rabbit), MyD88 (1:250, rabbit) and TLR4 (1:250, rabbit) were used, followed by Alexa Fluor 568 red fluorescence conjugated goat anti-rabbit as secondary antibodies (1:200) (Molecular Probes, Invitrogen, Eugene, OR, USA).

Subsequently, cells were incubated with
Alexa Fluor 488 phalloidin green fluorescence conjugate (1:400, Molecular Probes, Milan, Italy), to mark the cytoskeleton actin. Before mounting for microscope observation, samples were briefly washed in distilled water and cell nuclei stained with TOPRO (1:200, Molecular Probes) for $1 \mathrm{~h}$ at $37^{\circ} \mathrm{C}$ (Table 1$)$.

Staining was visualized using a Zeiss LSM 510 Meta confocal system (Zeiss, Jena, Germany), connected to an inverted Zeiss Axiovert 200 microscope equipped with a Plan Neofluar oil-immersion objective (63X). Images were collected using an argon laser beam with excitation lines at $488 \mathrm{~nm}$ and a helium-neon source at 543 and $665 \mathrm{~nm}$.

\section{Western blot analysis}

Proteins $(30 \mu \mathrm{g})$ from treated and untreated hPDLSCs were processed as previously described..$^{15}$ Proteins were separated on SDS-PAGE and subsequently transferred to nitrocellulose sheets using a semidry blotting apparatus. Sheets were saturated for $60 \mathrm{~min}$ at $37^{\circ} \mathrm{C}$ in blocking buffer (1xTBS, 5\% milk, $0.05 \%$ Tween-20), then incubated overnight at $4^{\circ} \mathrm{C}$ in blocking buffer containing primary antibodies to TLR4 (1:500), ERK 1/2 (1:750), p-ERK 1/2 (1:1000), NFkB (1:500), MyD88 $(1 \mu \mathrm{g} / \mathrm{ml})$ and $\beta$-actin $(1: 1000)$. After four washes in TBS containing $0.1 \%$ Tween-20, samples were incubated for $30 \mathrm{~min}$ at room temperature with peroxidase-conjugated secondary antibody diluted $1: 1000$ in $1 \mathrm{x}$ TBS, 5\% milk, 0.05\% Tween-20. Bands were visualized by the ECL method (16). The level of recovered protein was measured using the Bio-Rad (Bio-Rad Laboratories, Hercules, CA, USA) Protein Assay (detergent compatible) according to the manufacturer's instructions.

\section{Cytokines assays}

hPDLSCs cells were cultured in 6-well and treated with LPS-G $(5 \mu \mathrm{g} / \mathrm{mL})$. The supernatants of treated and untreated hPDLSCs, after $24 \mathrm{~h}$ of culture, were collected and subsequently were analyzed by RayBio Human Cytokine Antibody Array kit (Ray Biotech, Norcross, GA, USA) to identify the expression profile of multiple cytokines: Eotaxin, Eotaxin 2, GCSF, GMCSF, ICAM-1, I-309, IL-1 $\alpha$, IL-1 $\beta$, IL-2, IL-3, IL-4, IL-6 IL6sR, IL-7, IL-8, IL-10, IL-11，IL-12p40, IL-12p70, IL-13, IL-15, IL-16, IL-17, IP-10, MCP-1 MCP-2, MCSF, MIG, MIP-1 $\alpha$, MIP-1 $\beta$, MIP-1d, RANTES, TGF- $\beta 1$, TNF- $\alpha$, TNF- $\beta$, STNF RI, STNF R2, PDGF-BB and TIMP-2. The test was done according to manufacturer's instructions.

\section{Statistical analysis}

Statistical analyses were performed with Graph Pad Prism 6.0 (GraphPad Software, La Jolla, CA, USA). Differences between groups were determined using the Student's $t$-test. Data were expressed as means \pm SEM. A P-value $<0.05$ was considered statistically significant.

\section{Results}

\section{Cells characterization and proliferation}

hPDLSCs were cultured in xeno free medium for their selective proliferation. After culturing, cells with stable fibroblastlike phenotype were used for testing (Figure1A). Human PDLSCs treated with LPS-G $5 \mu \mathrm{g} / \mathrm{mL}$ for $24 \mathrm{~h}$ showed a low density and some morphological modification, as large number of cytoplasmic process

Table 1. Antibodies used.

\begin{tabular}{|c|c|c|c|c|c|c|}
\hline Antibody & Supplier & Species & Dilution & Buffer solution & Incubation time & Temperature \\
\hline \multicolumn{7}{|c|}{ Primary antibodies } \\
\hline NFkB & $\begin{array}{c}\text { Origene } \\
\text { (Rockville, MD, USA) }\end{array}$ & Rabbit & 1:200 & Milk 2.5\% & Overnight (12 h) & $4^{\circ} \mathrm{C}$ \\
\hline $\begin{array}{l}\text { ERK } 1 / 2 \\
\text { p-ERK } 1 / 2 \\
\text { MyD88 } \\
\text { TLR4 }\end{array}$ & $\begin{array}{c}\text { Pierce } \\
\text { (Thermo Fischer, Life } \\
\text { Technologies, } \\
\text { Milan, Italy) }\end{array}$ & $\begin{array}{l}\text { Rabbit } \\
\text { Rabbit } \\
\text { Rabbit } \\
\text { Rabbit }\end{array}$ & $\begin{array}{l}1: 100 \\
1: 1000 \\
1: 250 \\
1: 250\end{array}$ & $\begin{array}{l}\text { Milk 2.5\% } \\
\text { Milk 2.5\% } \\
\text { Milk 2.5\% } \\
\text { Milk 2.5\% }\end{array}$ & $\begin{array}{l}\text { Overnight }(12 \mathrm{~h}) \\
\text { Overnight }(12 \mathrm{~h}) \\
\text { Overnight }(12 \mathrm{~h}) \\
\text { Overnight }(12 \mathrm{~h})\end{array}$ & $\begin{array}{l}4^{\circ} \mathrm{C} \\
4^{\circ} \mathrm{C} \\
4^{\circ} \mathrm{C} \\
4^{\circ} \mathrm{C}\end{array}$ \\
\hline \multicolumn{7}{|c|}{ Secondary antibodies } \\
\hline $\begin{array}{l}\text { Alexa-Fluor } 568 \\
\text { Alexa-Fluor } 488 \\
\text { TO-PRO }\end{array}$ & $\begin{array}{l}\text { Applied Biosystem } \\
\text { (Life Technologies, } \\
\text { Milan, Italy) }\end{array}$ & $\begin{array}{c}\text { Anti-rabbit } \\
- \\
-\end{array}$ & $\begin{array}{l}1: 200 \\
1: 200 \\
1: 200\end{array}$ & $\begin{array}{l}\text { Milk 2.5\% } \\
\text { Milk 2.5\% } \\
\text { Milk 2.5\% }\end{array}$ & $\begin{array}{l}1 \mathrm{~h} \\
1 \mathrm{~h} \\
1 \mathrm{~h}\end{array}$ & $\begin{array}{l}37^{\circ} \mathrm{C} \\
37^{\circ} \mathrm{C} \\
37^{\circ} \mathrm{C}\end{array}$ \\
\hline
\end{tabular}


(Figure 1B). The MTT assay showed significantly higher cell viability $(\mathrm{P}<0.01)$ in ctrl hPDLSCs compared to LPS-G exposed cells (Figure 1C). Cell viability decreased up to $15-20 \%$ in LPS-G exposed groups after 48 and $72 \mathrm{~h}$ of culture. Trypan blue exclusion test was performed to calculate the number of viable hPDLSCs and hPDLSCs treated with $5 \mu \mathrm{g} / \mathrm{mL}$ of LPS-G. Graphs showed a decrease in survival rate when compared with the control groups (Figure 1D).

\section{TLR4 expression}

TLR4 immunostaining showed a higher expression in hPDLSCs after exposure to LPS-G (Figure 1 E1) when compared to untreated cells (Figure 1 F1). Western blots and their densitometric analysis confirmed results obtained at confocal laser scanning microscopy (Figure $1 \mathrm{G}, \mathrm{H}$ ). Beta actin has been used as housekeeping protein (Figure $1 \mathrm{G)}$.

\section{Immunofluorescence staining}

To test whether LPS-G modulates signal intracellular pathway we investigated the expression of ERK $1 \frac{1}{2}, \mathrm{p}-\mathrm{ERK}^{1} / 2, \mathrm{NFkB}$ and MyD88 during treatment with $5 \mu \mathrm{g} / \mathrm{mL}$ of LPS-G. Immunofluorescence staining and confocal microscopy showed that LPS$\mathrm{G}$ treatment produced an increase of ERK $1 / 2$ (Figure 2 B2), p-ERK $1 \frac{1}{2}$ (Figure 2 D2), NFkB (Figure 2 F2) and MyD88 (Figure 2 D2) compared to untreated hPDLSCs. In particular, in Figure 2 section F2 inset NFkB showed a nuclear translocation in cells after exposure to $5 \mu \mathrm{g} / \mathrm{mL}$ LPS-G.

\section{Western blot analysis}

Western blotting analysis showed, an up-regulation of the ERK $1 / 2, M y D 88, N F k B$ and $p$-ERK $1 / 2$ in treated samples after $24 \mathrm{~h}$ of treatment, compared to ctrl sample (Figure 2I). Beta actin has been used as housekeeping protein (Figure 2I). Densitometric analysis of protein represents volume quantification of specific bands (Figure 2J).

\section{Cytokines release}

To examine the general effects of LPS$\mathrm{G}$ on hPDLSCs, we analyzed the release of the pro-inflammatory cytokines. For this purpose, supernatant obtained from ctrl hPDLSCs and hPDLSCs treated with LPS$\mathrm{G}$ were collected after $24 \mathrm{~h}$ of stimulus. Based on cytokine array data, we used a template set composed of multiple cytokines (Figure 3C). Spots marked on membranes indicate the modulated cytokines (Figure 3 A,B).

Figure 3D shows significative statistically differences cytokines expression in cells treated with LPS-G, in particular an upregulation of the secretion of IL- $1 \alpha$, IL8, IL-15, Eotaxin, Eotaxin 2, M-CSF, TGF- $\beta 1$, TNF- $\alpha$ and TNF- $\beta$ has been detected respect to control cells. On the contrary, a decrease of IL-10 and TIMP-2 was detected.
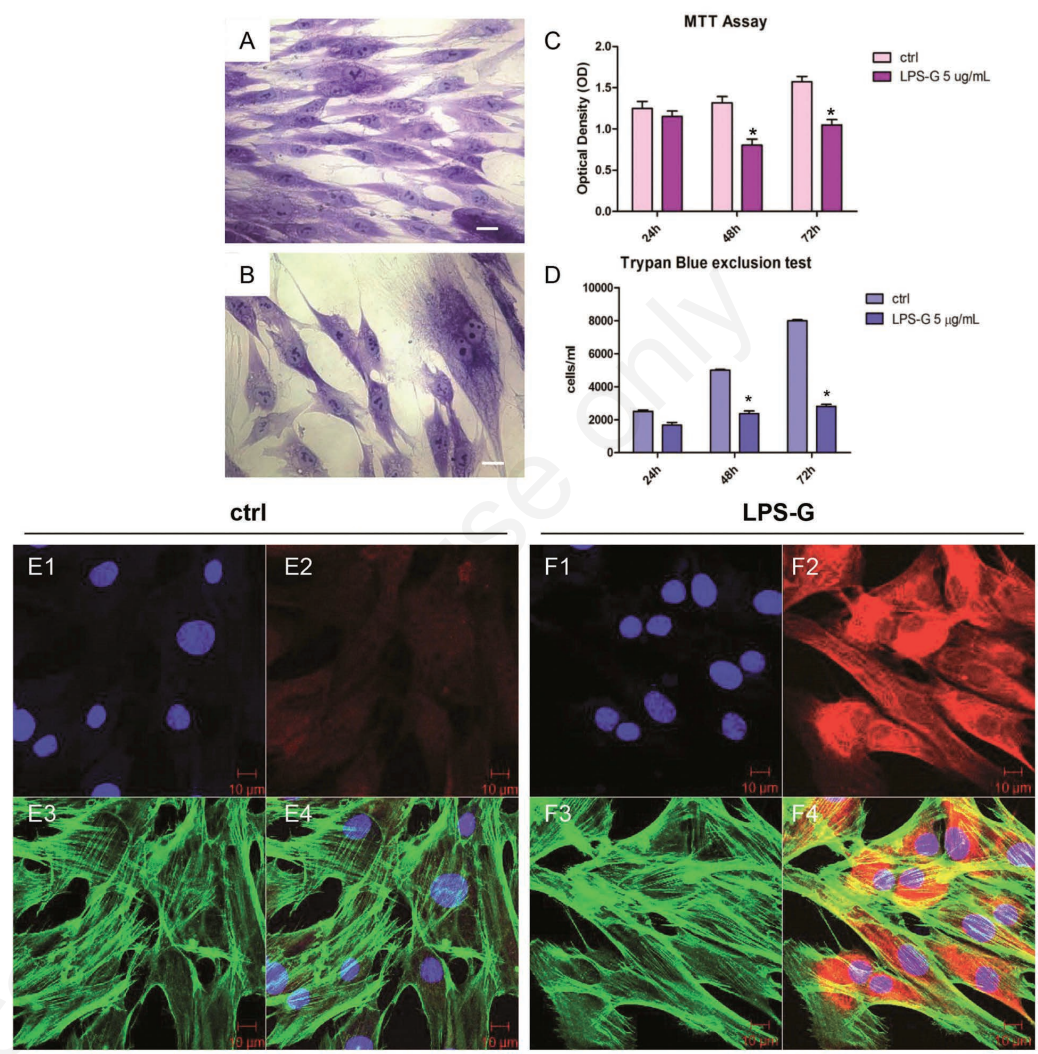

G

$\mathrm{H}$

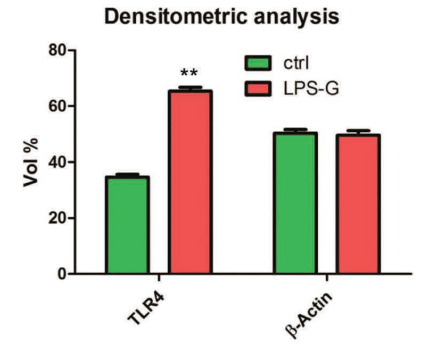

Figure 1. Morphology, viability, proliferation and TLR4 expression. Representative light microscopy image of untreated (A) and treated hPDLSCs (B) with LPS-G $5 \mu \mathrm{g} / \mathrm{mL}$, stained with methylene blue solution. hPDLSCs proliferation and viability were regulated during stimulation with LPS-G $5 \mu \mathrm{g} / \mathrm{mL}$. Proliferation was evaluated by MTT assay (C) and viability by means trypan blue exclusion test (D). Data are expressed as mean \pm SEM from 3 independent experiments with 5 replicates $\left({ }^{*} \mathrm{P}<0.05\right)$. Scale bars: $10 \mu \mathrm{m}$. Nuclei stained with TO-PRO (blue) (E1), TLR4 negative expression (red) (E2), cytoskeleton actin (green) (E3) and merge image (E4) of above three channels in untreated hPDLSCs. Nuclei stained with TO-PRO (blue) (F1), TLR4 positive expression (red) (F2), cytoskeleton actin (green) (F3) and merge image (F4) of above three channels in LPS-G treated hPDLSCs. Representative western blot (G) and its corresponding densitometric analyses $(\mathrm{H})$ of protein extracts from untreated (ctrl) and treated (LPS-G) hPDLSCs: TLR4. $\beta$-actin was used as housekeeping protein. Experiments were carried out in triplicate. Statistical analyses revealed a significant difference as follows: $(\mathrm{H}){ }^{* *} \mathrm{P}<0.01$ ctrl $v$ s LPS-G $5 \mu \mathrm{g} / \mathrm{mL}$; Scale bars: $10 \mu \mathrm{m}$. 
sythia and Aggregatibacter actinomycetemcomitans. ${ }^{17}$ LPS from Porphyromonas gingivalis has been identified as the master factor inducing periodontal disease.

Toll-like receptors (TLRs) are the major cell-surface initiators of inflammatory responses to pathogens. In particular, TLR4 represents the first recognition receptor pattern for LPS triggering the up-regulation of interleukin (IL)-6, IL-1 $\beta,{ }^{18}$ and tumor necrosis factor (TNF)- $\alpha$ in periodontitis. ${ }^{19}$ The responses to Porphyromonas gingivalis are strongly different among individuals, ${ }^{20}$ and previous studies stated that $5 \mu \mathrm{g} / \mathrm{mL}$ of LPS-G for $24 \mathrm{~h}$ was identified as the optimal dosage/time to induce the strongest inflammation in hGFs. ${ }^{21}$ Based on this evidence we have carried out our experiments by inducing in hPDLSCs an inflammatory process using $5 \mu \mathrm{g} / \mathrm{mL}$ LPS-G for $24 \mathrm{~h}$.

In the first istance we have focused our attention on the evaluation of TLR4 expression in hPDLSCs and in hPDLSCs treated with LPS-G. The results obtained in the treated samples put in evidence an increased expression of TLR4 surface receptor, evidenced trough immunohistochemistry and western blotting analysis. Considering that all TLRs, with the exception of TLR3, employ the adaptator protein MyD88 (Myeloid differentiation pathway) as signal machinery, ${ }^{22}$ we have evaluated MyD88 expression in treated hPDLSCs. It has been previously described that: i) TLR4 and MyD88 signaling results in the activation of downstream kinases leading to the degradation of $\mathrm{I} \kappa \mathrm{B}$, which frees $\mathrm{NF}-\kappa \mathrm{B}$ to translocate to the nucleus where it binds $\kappa \mathrm{B}$ sites in the promoter region of genes encoding pro-inflammatory cytokines; ${ }^{23}$ and ii) the overexpression of the complex TLR4/MyD88 habitually induces proinflammatory cytokines cascade. ${ }^{24}$

In our experimental model LPS-G stimulus induces an upregulation of MyD88 and NFkB levels besides NFkB nuclear translocation. Furthermore, the NF- $\kappa \mathrm{B}$ pathways activate MAPK3/1 (also known as ERK1/2) members of the Mitogen-activated Protein Kinase (MAPK) in response to TLR ligand binding. In fact, the protein level expression of p-ERK and ERK appears upregulated in treated samples. Moreover, LPS-G provokes the release of the following cytokines after $24 \mathrm{~h}$ of treatment: IL-1 $\alpha$, IL-8, IL-15, Eotaxin, Eotaxin 2, M-CSF, TGF- $\beta 1$, TNF$\alpha$ and TNF- $\beta$.

Among the released citokines, IL-1 $\alpha$ represents an important regulatory molecule during inflammatory process, ${ }^{25}$ and it is the most potent known inducer of bone demineralization, as well as, major changes in connective tissue matrix. ${ }^{26}$ IL- 8 is a chemoattractant and a potent angiogenic factor, ${ }^{27}$ TNF- $\alpha$ and $\beta$ are able to activate NFkB signaling, ${ }^{28}$ while Eotaxin is a eosinophil chemoattractant. ${ }^{29}$ TNF- $\alpha$ and IL-1 $\beta$ inhibit the osteogenic commitment of bone marrow stem cells, TNF- $\alpha$ activates $\mathrm{I} \kappa \mathrm{B}$ kinase $(\mathrm{IKK}) / \mathrm{NF} \kappa \mathrm{B}$ to down-regulate MSCs osteogenic differentiation. ${ }^{30}$ IL-10 limits the pro-inflammatory activities of
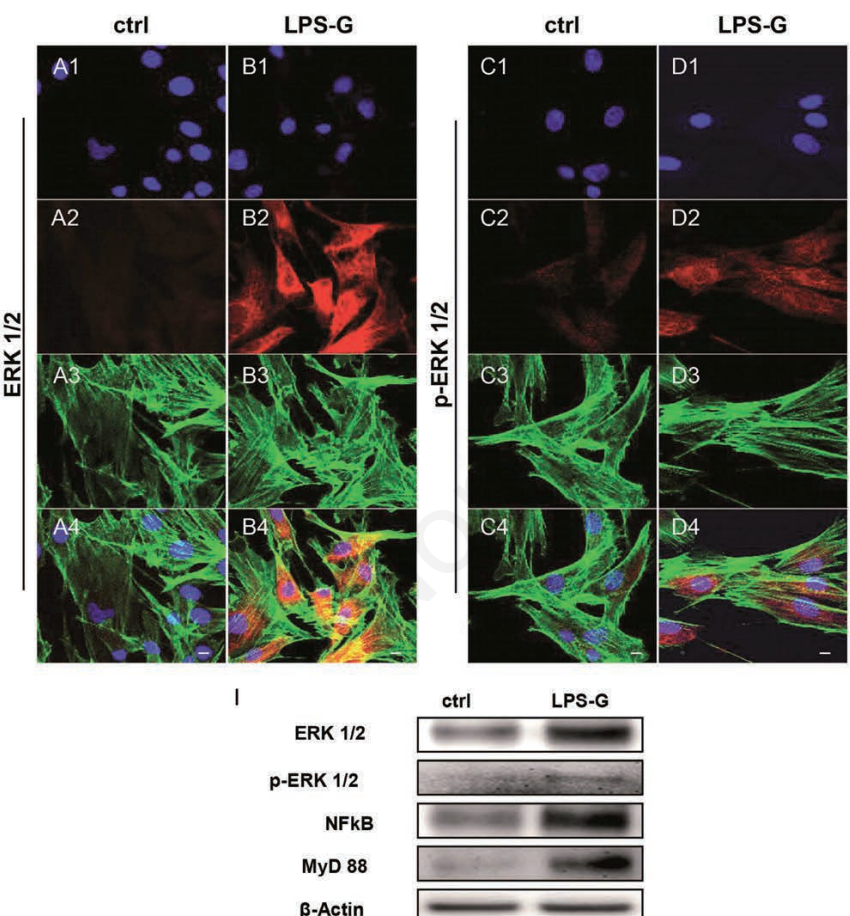

ctrl

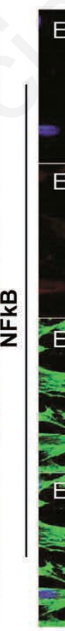

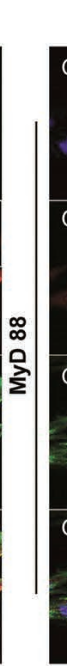
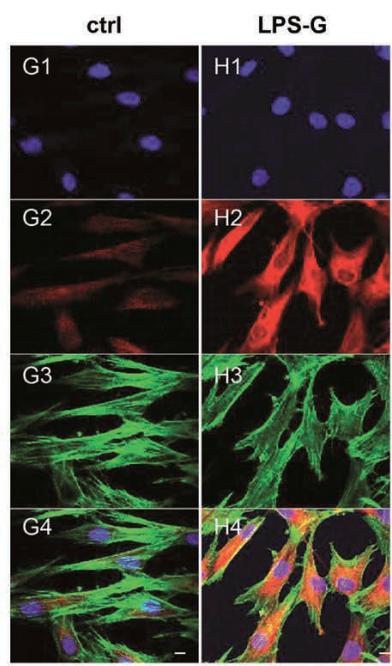

J

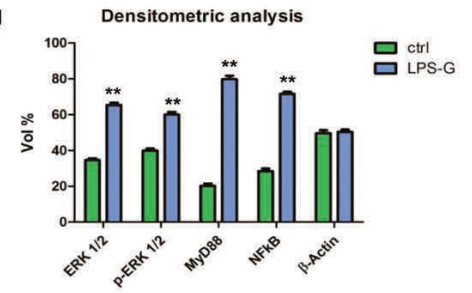

Figure 2. Expression and localization of ERK $1 \frac{1}{2}$, p-ERK $1 / 2$, NFkB and MyD 88 in hPDLSCs treated with $5 \mu \mathrm{gg} / \mathrm{mL}$. Nuclei stained with TO-PRO (blue) in (A1, C1, E1, G1) untreated and (B1, D1, F1, H1) treated hPDLSCs with LPS-G 5 Mg/mL. Expression of ERK $1 \frac{1}{2}$, pERK $1 \frac{1}{2}, \mathrm{NFkB}$ and MyD 88 (red) in untreated (A2, C2, E2, G2) and treated (B2, D2, F2, H2) hPDLSCs. TLR4 nuclear translocation hPDLSCSs treated with LPS-G (F2, inset). Phalloidin staining of cytoskeleton actin (green) in untreated (A3, C3, E3, G3) and treated (B3, D3, F3, H3) hPDLSCs. Merged images of above three channels in untreated (A4, C4, E4 and G4) and treated (B4, D4, F4 and H4) hPDLSCs. Experiments were carried out in triplicate. Scale bars: $10 \mu \mathrm{m}$. Representative Western blots (I) and their corresponding densitometric analyses (J) of protein extracts from untreated (ctrl) and treated (LPS-G) hPDLSCs with LPS-G 5 Hg/mL: ERK $1 / 2$, pERK $1 / 2$, MyD88 and NFkB. $\beta$-actin expression was used as housekeeping protein. Experiments were carried out in triplicate. Statistical analyses revealed a significant difference as follows: $(\mathrm{J}){ }^{* *} \mathrm{P}<0.01 \mathrm{ctrl} v s \mathrm{LPS}-\mathrm{G} 5 \mu \mathrm{g} / \mathrm{mL}$. 
$\mathrm{PMN}^{31,32}$ and generally improves wound repair during periodontitis. In LPSG/hPDLSCs a down-regulation of the IL-10 secretion occurs after $24 \mathrm{~h}$ of treatment.

Since in vivo periodontium homeostasis is kept by the balance between active MMPs and TIMPs, and their disturbance can induce many chronic inflammatory dis- eases, the down-regulation of TIMP and IL10 observed in the LPS-G/hPDLSCs treated, can contribute to explain the key role of the LPS in the inflammatory process leading in the perdiodontal tissue destruction in vivo. In synthesis, our study platform can represent an appropriate stem cells niche model leading to understand and evaluate
A

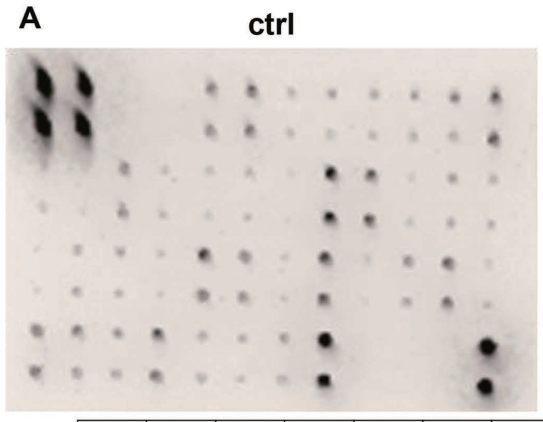

B

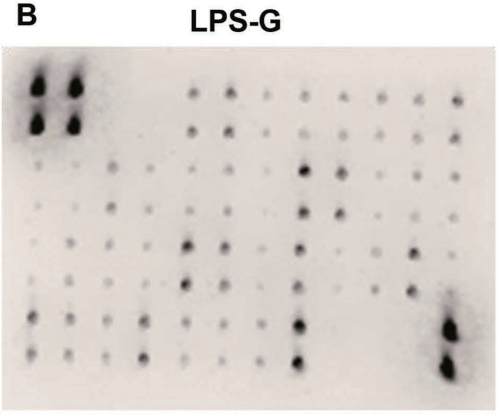

C

\begin{tabular}{|c|c|c|c|c|c|c|c|c|c|c|c|c|}
\hline & A & B & C & D & $E$ & $\mathrm{~F}$ & G & $\mathrm{H}$ & 1 & $\mathrm{~J}$ & K & L \\
\hline 1 & + & + & - & - & $\begin{array}{c}\text { EOTAXI } \\
\mathrm{N}\end{array}$ & \begin{tabular}{|c|} 
EOTAXI \\
N2
\end{tabular} & GCSF & GM-CSF & ICAM-1 & IFN-Y & 1-309 & IL-1 $\alpha$ \\
\hline 2 & + & + & . & - & $\begin{array}{c}\text { EOTAXI } \\
\mathrm{N}\end{array}$ & \begin{tabular}{|l|} 
EOTAXI \\
N2
\end{tabular} & GCSF & GM-CSF & ICAM-1 & IFN-Y & 1-309 & IL-1 $1 \alpha$ \\
\hline 3 & $\mathrm{IL}-1 \beta$ & $\mathrm{II}-2$ & IL-3 & IL-4 & II-6 & IL6sR & 1L-7 & 1L-8 & IL-10 & IL-11 & $\begin{array}{c}\text { 1L- } \\
12 \mathrm{p} 40\end{array}$ & \begin{tabular}{|c} 
11- \\
$12 \mathrm{p} 70$
\end{tabular} \\
\hline 4 & $\mathrm{IL}-1 \beta$ & $\mathrm{IL}-2$ & IL-3 & IL-4 & IL-6 & IL6sR & IL-7 & 1L-8 & IL-10 & $\mathrm{IL}-11$ & $\begin{array}{c}\text { IL- } \\
12 \mathrm{p} 40\end{array}$ & \begin{tabular}{|c} 
IL- \\
$12 \mathrm{p} 70$
\end{tabular} \\
\hline 5 & $11-13$ & II- -15 & IL-16 & IL-17 & |P-10 & MCP-1 & MCP-2 & M-CSF & MIG & MIP-1 $1 \alpha$ & MIP- $1 \beta$ & MIP-18 \\
\hline 6 & $11-13$ & IL-15 & IL-16 & IL-17 & |P-10 & MCP-1 & MCP-2 & M-CSF & MIG & MIP-1 $1 \alpha$ & MIP- $1 \beta$ & MIP-18 \\
\hline 7 & \begin{tabular}{|l} 
RANTES \\
\end{tabular} & TGF- $\beta 1$ & TNF- $\alpha$ & TNF- $\beta$ & $\begin{array}{c}\text { STNF } \\
\text { R1 }\end{array}$ & $\begin{array}{c}\text { STNF } \\
\text { R2 }\end{array}$ & \begin{tabular}{|c} 
PDGF- \\
BB
\end{tabular} & \begin{tabular}{|l|} 
TIMP-2 \\
\end{tabular} & BLANK & BLANK & - & + \\
\hline 8 & \begin{tabular}{|l} 
RANTES \\
\end{tabular} & TGF- $\beta 1$ & TNF- $\alpha$ & TNF- $\beta$ & $\begin{array}{c}\text { STNF } \\
\text { R1 }\end{array}$ & $\begin{array}{c}\text { STNF } \\
\text { R2 }\end{array}$ & $\begin{array}{c}\text { PDGF- } \\
\text { BB }\end{array}$ & \begin{tabular}{|l} 
TIMP-2 \\
\end{tabular} & BLANK & BLANK & - & + \\
\hline
\end{tabular}

D

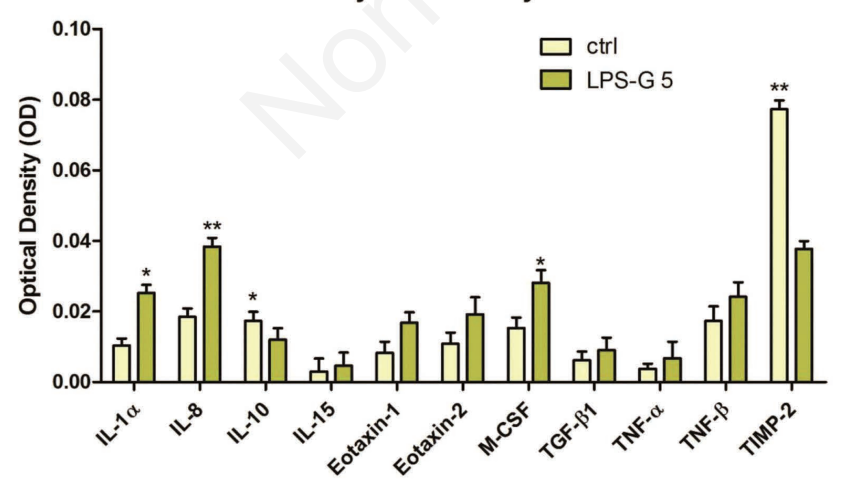

Figure 3. Cytokines release in hPDLSCs in hPDLSCs treated with $5 \mu \mathrm{g} / \mathrm{mL}$. Cytokines and chemokines release was analysed in medium from untreated and treated hPDLSCs with LPS-G $5 \mu \mathrm{g} / \mathrm{mL}$ hPDLSCs cultures. A, B) Representative arrays used to assess cytokines secreted by primary ctrl hPDLSCs (ctrl) and treated with LPS-G $5 \mu \mathrm{g} / \mathrm{mL}$ (LPS-G); spots on each array represent individual cytokines. C) Table that represents the correspondent membrane cytokine detectable; the upper eight spots on the left corner and the downer four spots on the right of each array are internal standards provided with the array. Spot intensities were quantified densitometrically for each cytokine. D) quantitative data for cytokines whose secretion was significant in cells treated with LPS-G respect to the ctrl cells. Data were expressed as mean $\pm \mathrm{SEM}\left({ }^{*} \mathrm{P}<0.05,{ }^{*} \mathrm{P}<0.01\right)$. the biological machinery of periodontal stem cells in response to LPS-G, mimicking in vitro an inflammatory process occurring in vivo. Further studies are needed to enhance our understanding of periodontal pathogenesis.

\section{References}

1. Nagatomo K, Komaki M, Sekiya I, Sakaguchi Y, Noguchi K, Oda S, et al. Stem cell properties of human periodontal ligament cells. J Periodont Res 2006;41:303-10.

2. Seo BM, Miura M, Gronthos S, Bartold PM, Batouli S, Brahim J, et al. Investigation of multipotent postnatal stem cells from human periodontal ligament. Lancet 2004;364:149-55.

3. Savage A, Eaton KA, Moles DR, Needleman I. A systematic review of definitions of periodontitis and methods that have been used to identify this disease. J Clin Periodontol 2009;36:45867.

4. Beutler B, Rietschel ET. Innate immune sensing and its roots: the story of endotoxin. Nat Rev Immunol 2003;3:16976.

5. Darveau RP. Periodontitis: a polymicrobial disruption of host homeostasis. Nat Rev Microbiol 2010;8:481-90.

6. Tabeta K, Yamazaki K, Akashi S, Miyake K, Kumada H, Umemoto T, et al. Toll-like receptors confer responsiveness to lipopolysaccharide from Porphyromonas gingivalis in human gingival fibroblasts. Infect Immun 2000;68:3731-5.

7. Rajan TS, Scionti D, Diomede F, Grassi G, Pollastro F, Piattelli A, et al. Gingival stromal cells as an in vitro model: cannabidiol modulates genes linked with amyotrophic lateral sclerosis. J Cell Biochem 2017;118:819-28..

8. Manescu A, Giuliani A, Mohammadi S, Tromba G, Mazzoni S, Diomede F, et al. Osteogenic potential of dualblocks cultured with human periodontal ligament stem cells: in vitro and synchrotron microtomography study. J Periodont Res 2016;51:112-24.

9. Diomede F, Zini N, Gatta V, Fulle S, Merciaro I, D'Aurora M, et al. Human periodontal ligament stem cells cultured onto cortico-cancellous scaffold drive bone regenerative process. Eur Cell Mater 2016;32:181-201.

10. Diomede F, Caputi S, Merciaro I, Frisone S, D'Arcangelo C, Piattelli A, et al. Pro-inflammatory cytokine release and cell growth inhibition in primary 
human oral cells after exposure to endodontic sealer. Int Endod $\mathrm{J}$ 2014;47:864-72.

11. Trubiani O, Piattelli A, Gatta V, Marchisio M, Diomede F, D'Aurora M, et al. Assessment of an efficient xenofree culture system of human periodontal ligament stem cells. Tissue Eng Part C Methods 2015;21:52-64. P

12. Trubiani $\mathrm{O}$, Toniato $\mathrm{E}$, Di Iorio $\mathrm{D}$, Diomede F, Merciaro I, C DA, et al. Morphological analysis and interleukin release in human gingival fibroblasts seeded on different denture base acrylic resins. Int J Immunopathol Pharmacol 2012;25:637-43.

13. Rajan TS, Giacoppo S, Trubiani O, Diomede F, Piattelli A, Bramanti P, et al. Conditioned medium of periodontal ligament mesenchymal stem cells exert anti-inflammatory effects in lipopolysaccharide-activated mouse motoneurons. Exp Cell Res 2016;349: 152-61.

14. Trubiani O, Guarnieri S, Diomede F, Mariggio MA, Merciaro I, Morabito C, et al. Nuclear translocation of PKCalpha isoenzyme is involved in neurogenic commitment of human neural crestderived periodontal ligament stem cells. Cell Signal 2016;28:1631-41.

15. Cataldi A, Zara S, Rapino $M$, Zingariello M, di Giacomo V, Antonucci A. p53 and telomerase control rat myocardial tissue response to hypoxia and ageing. Eur J Histochem 2009;53:e25.

16. Trubiani O, Giacoppo S, Ballerini $\mathrm{P}$, Diomede F, Piattelli A, Bramanti P, et al. Alternative source of stem cells derived from human periodontal ligament: a new treatment for experimental autoimmune encephalomyelitis. Stem Cell Res Ther 20164;7:1.

17. Jian CX, Li MZ, Zheng WY, He Y, Ren $\mathrm{Y}, \mathrm{Wu} \mathrm{ZM}$, et al. Tormentic acid inhibits LPS-induced inflammatory response in human gingival fibroblasts via inhibition of TLR4-mediated NF-kappaB and MAPK signalling pathway. Arch Oral Biol 2015;60:1327-32.

18. Leonardi R, Perrotta RE, Loreto C, Musumeci G, Crimi S, Dos Santos JN, et al. Toll-like receptor 4 expression in the epithelium of inflammatory periapical lesions. An immunohistochemical study. Eur J Histochem 2015;59:2547.

19. Di Benedetto A, Gigante I, Colucci S, Grano M. Periodontal disease: linking the primary inflammation to bone loss. Clin Dev Immunol 2013;2013:503754.

20. Scheres N, Laine ML, de Vries TJ, Everts V, van Winkelhoff AJ. Gingival and periodontal ligament fibroblasts differ in their inflammatory response to viable Porphyromonas gingivalis. J Periodont Res 2010;45:262-70.

21. Kang WY, Hu ZK, Ge SH. Healthy and inflamed gingival fibroblasts differ in their inflammatory response to Porphyromonas gingivalis lipopolysaccharide. Inflammation 2016;39:1842-52.

22. Brown J, Wang H, Hajishengallis GN, Martin M. TLR-signaling networks: an integration of adaptor molecules, kinases, and cross-talk. J Dent Res 2011; 90:417-27.

23. Taggart CC, Cryan SA, Weldon S, Gibbons A, Greene CM, Kelly E, et al. Secretory leucoprotease inhibitor binds to NF-kappaB binding sites in monocytes and inhibits p65 binding. J Exp Med 2005;202:1659-68.

24. Horng T, Medzhitov R. Drosophila MyD88 is an adapter in the Toll signaling pathway. Proc Natl Acad Sci USA 2001;98:12654-8

25. Zhang Y, Yu X, Lin D, Lei L, Hu B, Cao F, et al. Propiece IL-1alpha facilitates the growth of acute T-lymphocytic leukemia cells through the activation of NF-kappaB and SP1. Oncotarget 2017;8:15677-88.

26. Stashenko P, Dewhirst FE, Rooney ML,
Desjardins LA, Heeley JD. Interleukin1 beta is a potent inhibitor of bone formation in vitro. J Bone Miner Res 1987;2:559-65.

27. Laakkonen JP, Lappalainen JP, Theelen TL, Toivanen PI, Nieminen T, Jauhiainen S, et al. Differential regulation of angiogenic cellular processes and claudin- 5 by histamine and VEGF via PI3K-signaling, transcription factor SNAI2 and interleukin-8. Angiogenesis 2017;20:109-24.

28. Korneev KV, Atretkhany KN, Drutskaya MS, Grivennikov SI, Kuprash DV, Nedospasov SA. TLR-signaling and proinflammatory cytokines as drivers of tumorigenesis. Cytokine 2017;89:127-35.

29. Lilly CM, Nakamura H, Kesselman H, Nagler-Anderson C, Asano K, GarciaZepeda EA, et al. Expression of eotaxin by human lung epithelial cells: induction by cytokines and inhibition by glucocorticoids. J Clin Invest 1997;99: 1767-73.

30. Hong L, Sharp T, Khorsand B, Fischer C, Eliason S, Salem AK, et al. Correction: MicroRNA-200c represses IL-6, IL-8, and CCL-5 Expression and enhances osteogenic differentiation. PloS One 2016;11:e0169381.

31. Cianci E, Recchiuti A, Trubiani O, Diomede F, Marchisio M, Miscia S, et al. Human periodontal stem cells release specialized proresolving mediators and carry immunomodulatory and prohealing properties regulated by lipoxins. Stem Cells Transl Med 2016;5:20-32.

32. Giacoppo S, Gugliandolo A, Trubiani O, Pollastro F, Grassi G, Bramanti P, et al. Cannabinoid $\mathrm{CB} 2$ receptors are involved in the protection of RAW264.7 macrophages against the oxidative stress: an in vitro study. Eur J Histochem 2017;61:2749. 